\title{
Spatio-Temporal Analysis of Rainfall Variability and Meteorological Drought: A Case Study in Bilate River Basin, Southern Rift Valley, Ethiopia
}

\author{
Tamrat Lolaso Moloro* \\ Degree of Master of Science in Meteorology and Hydrology, Ethiopia
}

Submission: August 04, 2018; Published: September 25, 2018

*Corresponding author: Tamrat Lolaso Moloro, Degree of Master of Science in Meteorology and Hydrology, Ethiopia, Email: tamlolaso@gmail.com

\begin{abstract}
Rainfall always plays a deciding role in sustainable agricultural production. This research attends to analyzes variation of rainfall, examine trends of rainfall, evaluate the relationship between ENSO and rainfall variability, and analyzes meteorological drought in Bilate River Basin. The Bilate River Basin includes the portion of SNNPRS regional zones; Hadiya, Kanibate Tembaro, Gurage, Silte, Wolaita, Sidama, and Alaba special woreda and small parts of the South-central Oromiya Regional states. The analysis was done based on historical recorded rainfall data, 26 to 40 years (1974-2013) and ENSO data. Rainfall variability were analyzed through using basic statistics like mean, standard deviation, and coefficients of variation and trend were analyzed by non-parametric Mann-Kendall test methods. From the analysis Butajira both in Belg and Kiremt season rainfall were significant at $\alpha=.1, \alpha=.05, \alpha=.01$ level with critical statistic table value $1.645,1.96$, and 2.576 respectively. In addition to this, in Shone annual and Belg seasons were significant. In the study area El Niño enhances rainfall activities and La Niña periods lowering rainfall. La Nina episode decrease the amount of rainfall in Belg season and increase the amount of rainfall in Kiremt, while El Nino increase the amount of rainfall in Belg and decrease the amount of rainfall in Kiremt season of the regime. Drought is a natural feature of climate variability in all parts of world. The Standard Precipitation Index (SPI) method was used in this study to analyses major drought characteristics intensity, severity, duration, magnitude, frequency and spatial extents. The highest drought magnitude observed in Sodo when comparing with all seasons which magnitude is - 2.1 in SPI-3B and SPI-3K seasons. Next to Sodo is Shone and Hossana its magnitude is -1.88 in SPI -3B seasons. This study could help planners prepare proper forecasting for either long or short-term plans. Encourage to forecasting of El Niño and La Niña periods in each year's. Create awareness about meteorological droughts for society. Geographic Information System were used to generate drought severity maps for Belg and Kiremt seasons of recent eleven years, through using Ordinary Kriging method to interpolation and Coefficients of variations through Thiessen polygon method to interpolation.
\end{abstract}

Keywords: Rainfall Anomaly Index; ENSO; Standardized Precipitation Index; Drought; Trend and Rainfall Variability

\section{Introduction}

Drought is a natural feature of climate variability in all parts of the world, even in those having very different hydrological balances. Drought is a phenomenon that linked with a sustained lack of precipitation, and in some cases also which exceeds evapo-transpiration. It is difficult to define drought, since meteorological drought results from precipitation deficits, while agricultural drought is identified by total soil moisture deficits, and hydrological drought is related to a shortage of stream flow [1]. Another important feature of drought is their characteristic timescales, which can vary substantially. A single month of deficient rainfall can adversely affect rain fed crops while having virtually no impact on a large reservoir system [2].

Drought differs from one another in three essential characteristics: Intensity, duration, and spatial coverage. Intensity refers to the degree of the precipitation short fall and the severity of impacts associated the shortfall of rainfall. Drought is generally measured by the departure of some climatic index from normal and is closed linked to duration in the determination of impact. Many indices of drought are in widespread use today, such as the deciles approach [3] used in Australia, the Palmer drought severity index and crop moisture index [4] in the United States. The Standardized Precipitation index was developed [5] that was relatively new index and has been gaining increasing popularity in the United States and Worldwide. Another distinguishing feature of drought is its duration. Droughts usually require a minimum of two to three months to become established but then can continue for months or years. The magnitude of drought impacts is closely related to the timing of the rainfall shortage, its intensity, and the duration of the event. Droughts also differ in terms of their spatial characteristics. The areas affected by different drought intensity evolve gradually and regions of maximum intensity shift from season to season. 
In agricultural country like Ethiopia, reliable rainfall distribution is very important for successful rain fed agricultural. Rainfall is one essential parameter to determining agricultural productivity in Ethiopia. In each year normal rainfall distribution both in spatial and temporal scales of Belg and Kiremt including unseasonal rainfall is relevant for food production, drinking water, recharging ground water and hydroelectric power. However, the spatially and temporally distribution of rainfall in the country is irregular and erratic [6]. The economy of Ethiopia depends largely on rain-fed agriculture, which is highly sensitive to variability of rainfall across time and space. The recent drought years of 1965, 1972 - 73, 1983 - 84, 1987 - 88 and 1997 resulted in low agricultural production and affected millions of rural poor farmers, pastoralists, domestic and wild animals, with serious degradation of the environment [7].

\section{General Objective}

The overall goal of the research is to assess to the spatial and temporal rainfall variability and meteorological drought in Bilate River Basin.

\section{Specific Objectives}

a) To analyzes variation of rainfall in the space and time in the study area.

b) To examine trends of rainfall in the study area. c) To evaluate the relationship between ENSO and observed rainfall variability.

d) To analyzes meteorological drought and map drought intensity in the study area.

\section{Materials and Methods}

\section{Location of Study Area}

The study area of Bilate River Basin is located in South Western Escarpment of the Main Ethiopian Rift Valley region at about $130 \mathrm{Km}$ North West of the regional town Awassa and $340 \mathrm{~km}$ from Addis Ababa along the asphalt road from Addis Ababa to the Arbaminch town via Shashemane, Alaba Kulito, Wolaita Sodo of SNNPR. It accessible through $230 \mathrm{Km}$ asphalt road from Addis Ababa -Hossana in Northern part and Inter site accessibility is possible by currently made dry weather roads and other feeder dry-weather access roads that connect different parts of the study area. The Bilate River Basin includes the portion of SNNPRS regional zones; Hadiya, Kabate Tembaro, Gurage, Silte, Wolaita, Sidama, and Alaba special woreda and small parts of the South-central Oromiya Regional states. It covers an area of about 5625-kilometer square. It is bounded in geographic coordinates of $365483 \mathrm{E}$ to $426838 \mathrm{E}$ at Abaya Lake in southern part Wolaita Zone to $726037 \mathrm{~N}$ to $896469 \mathrm{~N}$ at Gurage and Silte zones border in the Northern part (Figure 1).

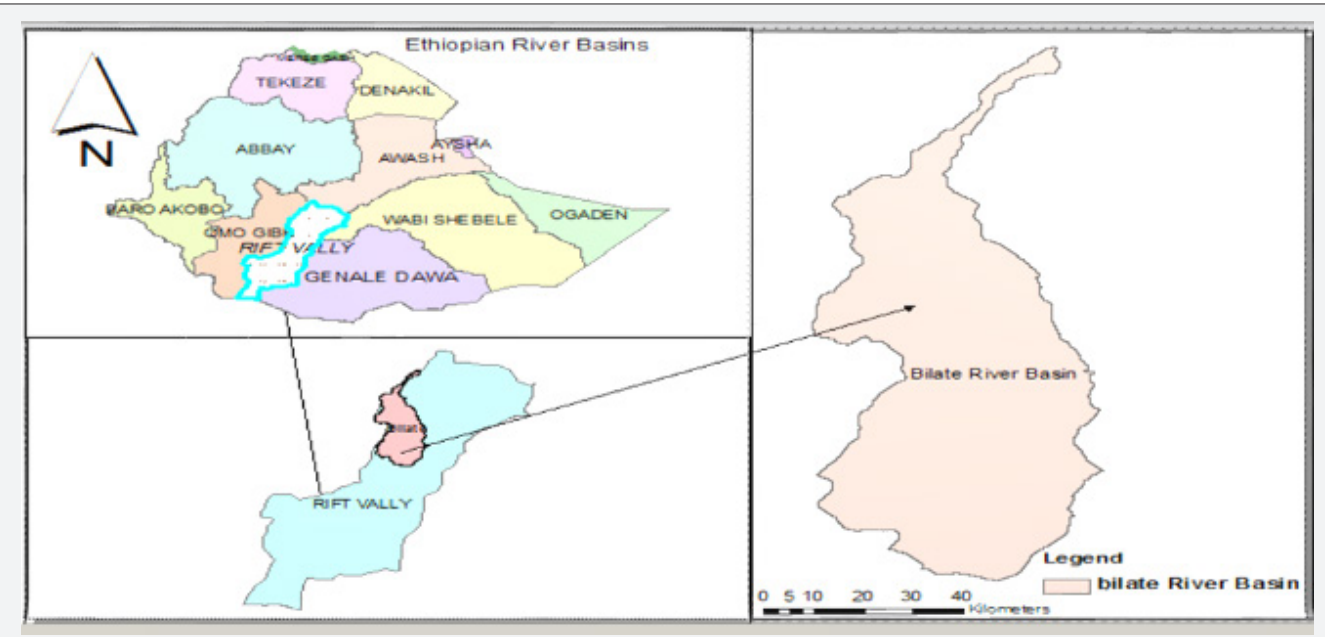

Figure 1: Location map of the study area (source Ethio-Gis).

\section{Data Collection}

Rainfall Data: Rainfall data obtained from secondary source of National Meteorological Agency. A total number observed monthly rainfall data were obtained from fourteen stations in the study area.

Sea Surface Temperatures (SST) Data: Sea surface temperatures (SSTs) (between $1 \mathrm{~mm}$ and $20 \mathrm{~m}$ below sea surface) from Niño 3.4 region, a region used for monitoring ENSO events (El Niño and La Niña) in the central Pacific Ocean $\left(5^{\circ} \mathrm{N}-5^{\circ} \mathrm{S} ; 120^{\circ}\right.$ $170^{\circ} \mathrm{W}$ ) were used. The data were acquired from the NOAA-Climate Prediction Center (CPC) website (NOAA, 2014).
Filling of Missing Data: The missing data at a station in its rainfall series data can be estimated by simple average methods as explained Abdissa. Each missing monthly data was calculated using the following equations:

Where is the missing precipitation data at the station $\mathrm{x}$

$\mathrm{M}_{\mathrm{y}}$ is Yearly total of the particular year.

$M_{t}$ is annual mean for the whole time series and $M_{m}$ is monthly mean for the whole time series.

$$
p_{x}=\left(\frac{M_{y}}{M_{t}}\right) M_{m}
$$




\section{Method of Data Analysis}

Analysis of Rainfall Variability: Analysis Variation of rainfall is important for planning and management of water resource intervention. Rainfall variability is expressed by the coefficient of variation (CV). CV is defined as the ratio of standard deviation to mean in percent, where mean and standard deviation are estimated from rainfall data. Rainfall variability analyzed through using basic statistics like mean, standard deviation, and coefficients of variation temporal and spatial variation of rainfall. Coefficient of variation is used to classified degree of Variability of rainfall as follows (NMSA, 1996):

$$
\mathrm{CV}=\mathrm{CV}=\sigma / \mathrm{x}^{*} 100
$$

where $\breve{x}=$ mean of $n$ number of rainfalls in $\mathrm{mm}, \sigma$ is standard deviation.

$\mathrm{CV}<20$ less variable, $\mathrm{CV} 20$ to 30 moderate variable, $\mathrm{CV}>30$ highly variable

To Study the Relationship Between ENSO Effects on Rainfall Variability: For comparison of two time series, the correlation $r$ is a common used statistical value, which states if two quantities are related, i.e. it is a measure of the strength of their relationship. The value of $r$ lies between -1 and 1 , with 1 for perfect positive correlation, so the correlated time series increase and decrease together, 0 for no correlation and -1 for perfect negative correlation. In this study it used for one objective, which the observed precipitation in station level correlation with ENSO, Belg and Kiremt seasons.

The correlation, or Pearson's r, is given by the following equation:

$$
R(X, Y)=\frac{\sum_{i}^{n}(X i-\bar{X})(Y i-\bar{Y})}{\sqrt{\sum_{i}^{n}(X-\bar{X})^{2} \sum_{i}^{n}(Y-Y)^{2}}}
$$

Here $\mathrm{R}(\mathrm{X}, \mathrm{Y})$ is the linear correlation coefficient, and are the mean values of $X$ and $Y$ which are RAI and ONI data. also, thus $\left.\left(\mathrm{X}_{\mathrm{i}}-\bar{X}\right)\right)$ and $\left(\mathrm{Y}_{\mathrm{i}}-\bar{Y}\right)$ are the anomalies of $\mathrm{X}$ and $\mathrm{Y}$. The correlation of anomalies of two different variables identified to each station. Those two different variables are rainfall and ENSO seasonal values.

Analyzes Rainfall Patterns and Distribution: Rainfall patterns were analyzed by number of months verses average monthly rainfall value in a station. In addition to that, annual and seasonal rainfall distribution analyzes.

Rainfall Anomaly Index (RAI): The rainfall anomaly index is calculated simply as the difference between the precipitation during a selected time scale for each year of the series and the precipitation average, divided by the standard deviation of the precipitation series for the selected timescale [8]. RAI primarily developed for analysis of drought that negative value indicates dryness and positive value indicates wetness.

Trend Analysis: Several tests are available for the detection and estimation of trends. Mann Kendall statistics (S) is one of the non-parametric statistical tests which were used for detecting trends of climatic variables in this study. Mann-Kendall's test is a non-parametric method, which is less sensitive to outliers and test for a trend in a time series without specifying whether the trend is linear or nonlinear [9]. The Mann-Kendall's test statistics (S) is given as [10].

$$
S=\sum_{i=1}^{n-1}\left[\sum_{j=i+1}^{n} \operatorname{sign}\left(X_{i}-X_{j}\right)\right]
$$

Where $\mathrm{S}$ is the Mann-Kendal's test statistics; $\mathrm{x}_{\mathrm{i}}$ and $\mathrm{x}_{\mathrm{j}}$ are the sequential data values of the time series in the years $i$ and $j(j>i)$ and $\mathrm{N}$ is the length of the time series. A positive $\mathrm{S}$ value indicates an increasing trend and a negative value indicates a decreasing trend in the data series. The sign function is given as

$$
\operatorname{sgn}\left(X_{i}-X_{j}\right)=\left\{\begin{array}{c}
+1 \text { if }\left(X_{i}-X_{j}\right)>0 \\
0 \text { if }\left(X_{i}-X_{j}\right)=o \\
-1 \text { if }\left(X_{i}-X_{j}\right)<0
\end{array}\right.
$$

The variance of $S$, for the situation where there may be ties (that is equal values) in the $\mathrm{x}$ values, is given by:

$$
\operatorname{Var}(S)=\frac{1}{18}\left[N(N-1)(2 N+5)-\sum_{i=0}^{m} t_{i}\left(t_{i}-1\right)\left(2 t_{i}+5\right]\right.
$$

Where, $m$ is the number of tied groups in the data set and $t_{i}$ is the number of data points in the $\mathrm{i}^{\text {th }}$ tied group. For $\mathrm{n}$ larger than 10 , $\mathrm{Z}_{\mathrm{Mk}}$ approximates the standard normal distribution and computed as follows:

$$
Z_{M K}=\left\{\begin{array}{l}
\frac{S-1}{\sqrt{\operatorname{Var}(S)}} \text { if } S>0 \\
\frac{S+1}{\sqrt{\operatorname{Var}(S)}} \text { if } S<0 \\
0 \text { if } S=0
\end{array}\right.
$$

The presence of a statistically significant trend is evaluated using the $\mathrm{Z}_{\mathrm{MK}}$ value. In a two-sided test for trend, the null hypothesis Ho should be accepted if $/ \mathrm{Z}_{\mathrm{MK}} /<\mathrm{Z}_{1-\alpha / 2}$ at a given level of significance. $Z_{1-\alpha / 2}$ is the critical value of $Z_{\mathrm{MK}}$ from the standard normal table. Example for $5 \%$ significance level, the value of $\mathrm{Z}_{1-\alpha / 2}$ is 1.96 .

\section{Analysis of Drought}

SPI Program Fill: The program to compute SPI for different time scales (e.g. 1, 3, 6...) is already compiled and all libraries are included (it is compiled in C++ for PC). The input files should be prepared for each station in the format.

Header

Yyyy mm pp

Yyyy mm pp

уyуy $\mathrm{mm}$ pp

Where Header $=$ describes the file name, or something about the station, etc, Yyyy = year, $\mathrm{mm}=$ month (in digit format 1, 2, 3 ...12), $\mathrm{pp}=$ monthly precipitation. The Yyyy mm and pp may be separated by either space or commas. In output, -99 denote missing values. 


\section{Software Packages Used in the Study}

ArcGIS9.3, use for spatial mapping of drought events and rainfall variability. All the statistical data were analyzed using Microsoft Excel 2007, trend software for detection of trends and SPI_SL_6.exe program to calculate SPI value (Table 1).

Table 1: Values of Standardized Precipitation Index (SPI) related to moisture conditions.

\begin{tabular}{|c|c|}
\hline SPI Value & Moisture Condition \\
\hline$+2>$ & extremely wet \\
\hline+1.5 to 1.99 & very wet \\
\hline+1.0 to 1.49 & moderately wet \\
\hline 0 to 0.99 & Mildly wet \\
\hline 0 to -.99 & Mild drought \\
\hline-1.0 to -1.49 & Moderately dry \\
\hline-1.5 to -1.99 & severely dry \\
\hline$-2<$ & Extremely dry \\
\hline
\end{tabular}

\section{Results and Discussion}

The result of the thesis presented into three parts based on the objectives set at the beginning. The first part analyzed rainfall variability, patterns, distribution and trends of rainfall, the second part investigate the relationship between ENSO and rainfall and finally analyzed the meteorological drought by their characteristics, clearly drought duration, intensity, severity, frequency and spatial extend mapping.

\section{Variability of Kiremt Rainfall}

Kiremt (June to September) is main rain season, which average value of June, July, August, and September. Coefficient for variation is kiremt. kiremt rainfall variability for some stations was high (CV nearly $>30 \%$ ) those stations are Bedesa, Bilate tena, Bilate farm state, Humbo Tebelea and Wolaita Sodo were highly variable during kiremt rain season. Among those in Wolaita Sodo station highly variable in kiremt season. In Hossiana and Butajira less variable, which CV value less $20 \%$. In addition to this Boditi, Alaba Kulito, Angacha, Fonko, Hawassa, and Shone were moderately variable which $\mathrm{CV}$ value $20 \%$ to $30 \%$. The results of analysis show that, $37.5 \%$ highly variable, $50 \%$ moderately rainfall variable and $14.3 \%$ less variable rainfall distribution. When we concluded the direct effects of Kiremt rainfall on agricultural production, high variability could tremendously affect the farming community in the study sites.

\section{Variability of Belg Rainfall}

Belg (February to May) is the small rain period. Belg rainfall CV can be seen from out of the total stations the maximum CV $33 \%$ in Fonko and minimum in Humbo Tebele station CV 20\% was observed which indicates highly variability rainfall in Belg season. In Angacha, Bilata fram, Bilate Tena, Alaba Kulito and Hossana were characterized as highly variable and Bedessa, Hawassa, Boditi, and Humbo Tebele were moderately variable which $\mathrm{CV}$ value $20 \%$ to $30 \%$. Belg rainfall in the study area showed highly variability $(\mathrm{CV}>30 \%)$. Comparing the seasonal variability of rainfall in the study area, Belg rainfall is more variable than the kiremt rainfall. In some station kiremt CV is greater than Belg, for instance Bedesa Kiremt CV $>31 \%$ whereas Belg for Hawassa $\mathrm{CV}>26 \%$ which is highly variable.

\section{Annual Rainfall Variability}

The coefficient of variation in most stations revealed that rainfall has moderately variability. The result indicated that annual rainfall at Alaba Kulito, Angacha, Bilata fram, Bilate Tena, Shone, Humbo Tebele, Wolaita Sodo, Butajira and Wilbereg were moderately variable. All the rest were less annual rainfall variable, which means the CV value less $20 \%$. In general, there is no more annual rainfall variability in Bilate River Basin but varies moderately. The total variability of annual rainfall accounts to an area of $57.1 \%$ moderately variable, $42.9 \%$ less rainfall variable and no highly variable rainfall distribution. The degree of annual rainfall variability decreases when compared to Belg and Kiremt seasons.

\section{Thiessen Polygon Method}

To estimate coefficients of variation distribution over the selected basin Thiessen Polygon method was implemented and used in this study, where the Coefficients' of variation shown in Tables 2-4 and map of CV in Figure 2. $\mathrm{Z}_{\mathrm{mk}}$ is Mann-Kendall trend test, Ns is non-significant trend and * indicates significant trend at $\alpha=.1, \alpha=.05, \alpha=.01$ level with critical statistic table value 1.645 , 1.96 , and 2.576 respectively. A positive value of $S$ indicates that there is an increasing trend and vice versa.

Table 2: Annual and seasonal rainfall coefficient of variation.

\begin{tabular}{|c|c|c|c|}
\hline Station & Kiremt CV & Belg CV & Annual CV \\
\hline Alaba Kulito & .29 & .37 & .23 \\
\hline Angacha & .27 & .32 & .23 \\
\hline Hawassa & .22 & .24 & .14 \\
\hline Bedessa & .31 & .26 & .17 \\
\hline Bilata fram & .32 & .33 & .23 \\
\hline Bilate Tena & .32 & .35 & .21 \\
\hline Boditi & .22 & .29 & .13 \\
\hline Butajira & .1 & .2 & .23 \\
\hline Wilbarega & .27 & .36 & .23 \\
\hline Hossana & .14 & .32 & .15 \\
\hline Humbo Tebele & .39 & .28 & .23 \\
\hline Shone & .28 & .34 & .28 \\
\hline Sodo & .41 & .35 & .29 \\
\hline Fonko & .15 & .33 & .16 \\
\hline
\end{tabular}




\section{International Journal of Environmental Sciences \& Natural Resources}

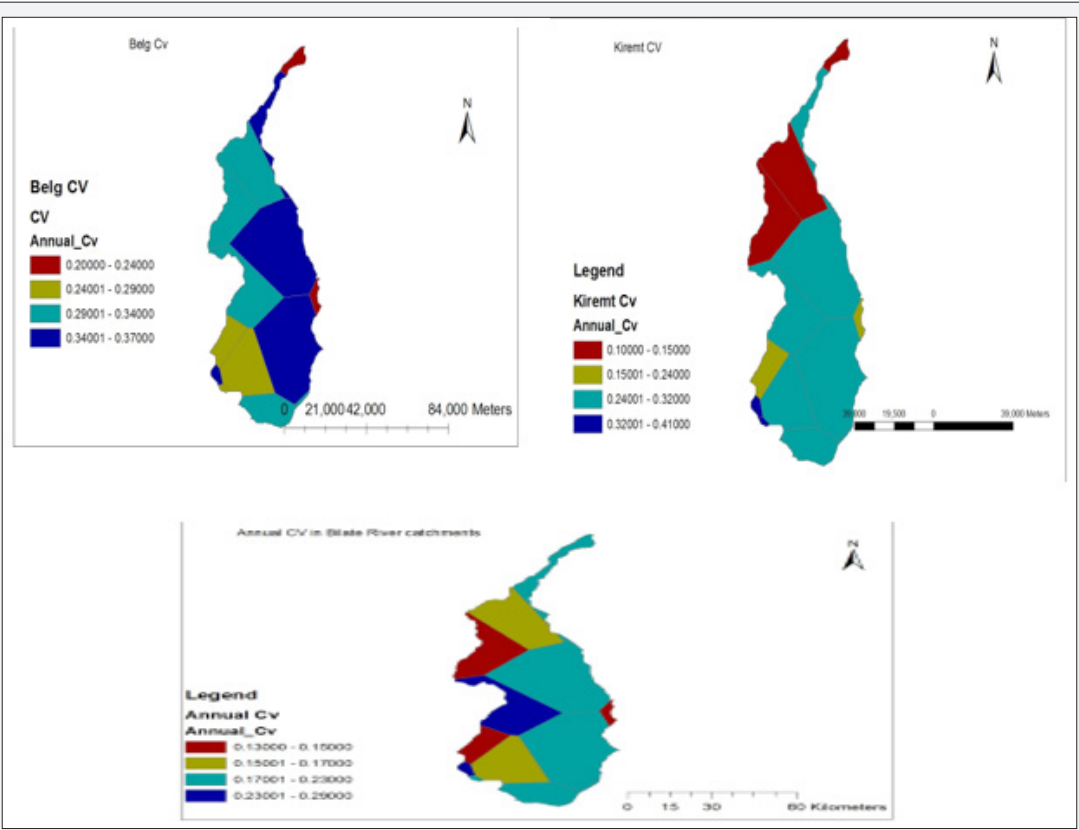

Figure 2: Spatial distribution of rainfall in the study area.

Table 3: The amount of Seasonal rainfall contributions in Bilate River basin.

\begin{tabular}{|c|c|c|c|}
\hline Station & Kiremt Rainfall \% & Belg Rainfall in \% & Bega Rainfall in \% \\
\hline Alaba Kulito & 45.2 & 39.4 & 15.4 \\
\hline Angacha & 50.1 & 35.2 & 14.7 \\
\hline Hawassa & 47.4 & 34.8 & 21.1 \\
\hline Bedessa & 40.23 & 38.15 & 22.2 \\
\hline Bilata fram & 38.3 & 39.5 & 21.1 \\
\hline Bilate Tena & 40 & 39.8 & 16.3 \\
\hline Boditi & 45.6 & 38 & 23.9 \\
\hline Butajira & 51.14 & 39.2 & 12.35 \\
\hline Hossana & 51.73 & 35.9 & 19.8 \\
\hline Humbo Tebele & 47.6 & 32.6 & 16.75 \\
\hline Shone & 45.4 & 35.3 & 18.3 \\
\hline Sodo & 46.54 & 33.19 & 9.9 \\
\hline Wilbarega & 56.87 & 37.01 & 12.6 \\
\hline Fonko & 50.33 & & \\
\hline
\end{tabular}

Table 4: Result of Mann-Kendall Test for 14 Selected Stations around in Bilate River Basin.

\begin{tabular}{|c|c|c|c|c|c|c|c|c|c|}
\hline \multirow{2}{*}{ Station } & \multicolumn{3}{|c|}{ Annual } & \multicolumn{3}{|c|}{ Kiremt Rainfall } & \multicolumn{3}{|c|}{ Belg Rainfall } \\
\hline & $\mathrm{Z}_{\mathrm{mk}}$ & S & Trend Detection & $\mathrm{Z}_{\mathrm{mk}}$ & $\mathbf{S}$ & Trend Detection & $\mathrm{Z}_{\mathrm{mk}}$ & $\mathbf{S}$ & Trend Detection \\
\hline Alaba Kulito & -0.04 & -4 & Ns & 1.19 & 92 & Ns & -1.1 & -80 & Ns \\
\hline Angacha & 0.46 & 23 & Ns & 1.04 & 52 & Ns & 0 & 0 & Ns \\
\hline Hawassa & -0.25 & -22 & Ns & -1.2 & -98 & Ns & 0.46 & 40 & Ns \\
\hline Bedessa & 1.17 & 57 & Ns & 1.21 & 59 & Ns & -0.8 & 0.39 & Ns \\
\hline Bilata fram & 1.3 & 91 & Ns & 1.2 & 76 & Ns & 0.1 & 7 & Ns \\
\hline
\end{tabular}




\section{International Journal of Environmental Sciences \& Natural Resources}

\begin{tabular}{|c|c|c|c|c|c|c|c|c|c|}
\hline Bilate Tena & 0.338 & 30 & Ns & -0.57 & -50 & Ns & -0.66 & -0.76 & Ns \\
\hline Boditi & -0.85 & -44 & Ns & 0.296 & 16 & Ns & -1.3 & -65 & Ns \\
\hline Butajira & -0.08 & -8 & Ns & 4.44 & 382 & $*$ & -8.1 & -692 & $*$ \\
\hline Hossana & 0.8 & 70 & Ns & 0.45 & 40 & Ns & 0.78 & 68 & Ns \\
\hline $\begin{array}{c}\text { Humbo } \\
\text { Tebele }\end{array}$ & 1.01 & 47 & Ns & 1.01 & 47 & Ns & -7 & -0.13 & Ns \\
\hline Shone & -2.4 & -210 & $*$ & -1.13 & -98 & Ns & -2.2 & -188 & $*$ \\
\hline Sodo & -0.64 & -56 & Ns & -0.41 & -36 & Ns & -1.5 & -130 & Ns \\
\hline Wilbarega & -1.5 & -128 & Ns & -1.1 & -96 & Ns & -1.5 & -128 & Ns \\
\hline Fonko & -1.1 & -51 & Ns & 1 & 49 & Ns & -1.2 & -57 & Ns \\
\hline
\end{tabular}

$\mathrm{Z}_{\mathrm{mk}}$ is Mann-Kendall trend test, Ns is non-significant trend and * indicates significant trend at $\alpha=.1, \alpha=.05, \alpha=.01$ level with critical statistic table value $1.645,1.96$, and 2.576 respectively. A positive value of $S$ indicates that there is an increasing trend and vice versa.

For the kiremt rainfall, increasing trends at Alaba Kulito, Angacha, Bedesa, Bilate farm state, Boditi, Hossana, Humbo Tebele and Fonko are statistically not significant but Butajira is significant trend at $\alpha=0.05$ level. The other significant trends are the decreasing kiremt rainfall at Awassa, Bilate Tena, Shone, Sodo and Wilberega. In addition to this, the decreasing Belg rainfall at Alaba Kulito, Angacha, Butajira, Bilate Tena, Shone, Sodo, Wilberega, Bilate farm state, Boditi, Humbo Tebele and Fonko and increasing in three stations out of fourteen stations those are Hossana, Hawassa and Bedesa that were statistically not significant. In Belg season in Butajira and Shone significant trends at $\alpha=0.05$ level and are the decreasing trends.
As shown in Table 5, the results indicate there are increasing trend in Angacha, Bedessa Bilata fram, Humbo Tebele, Hossana and Bilate Tena, whereas decreasing trend in Fonko, Hawassa, Butajira, Boditi, sodo, Shone, Wilbarega and Alaba Kulito of annual rainfall patterns. In general, nearly all stations rainfall are positively and negatively correlated with SSTA in FMA and JAS seasons respectively. In addition to this El Niño enhances rainfall activities and La Niña periods lowering rainfall. This finding is the same [11]. La Nina episode decrease the amount of rainfall in Belg season and increase the amount of rainfall in Kiremt, while El Nino increase the amount of rainfall in Belg and decrease the amount of rainfall in Kiremt season of the regime.

Table 5: Correlation coefficient of ENSO and RAI index.

\begin{tabular}{|c|c|c|c|c|}
\hline \multirow[t]{2}{*}{ Station } & \multicolumn{2}{|c|}{ JAS Season Correlation } & \multicolumn{2}{|c|}{ FMA Season Correlation } \\
\hline & Correlation & Category & Correlation & Category \\
\hline Alaba Kulito & -0.17 & Negative & .0 .013 & Positive \\
\hline Angacha & -0.038 & Negative & 0.06 & Positive \\
\hline Hawassa & -0.28 & Negative & 0.11 & Positive \\
\hline Bedessa & -0.4 & Negative & 0.15 & Positive \\
\hline Bilata state from & -0.31 & Negative & -0.013 & Negative \\
\hline Bilate Tena & -0.4 & Negative & -0.06 & Negative \\
\hline Boditi & -0.2 & Negative & -0.01 & Negative \\
\hline Butajira & -0.137 & Negative & 0.2 & Positive \\
\hline Hossana & -0.11 & Negative & 0.15 & Positive \\
\hline Humbo Tebele & -0.26 & Negative & -0.19 & Negative \\
\hline Shone & -0.01 & Negative & 0.204 & Positive \\
\hline Sodo & -0.3 & Negative & -0.1 & Negative \\
\hline Wilbareg & -0.19 & Negative & 0.1 & Positive \\
\hline Fonko & 0.09 & Positive & -0.04 & Negative \\
\hline
\end{tabular}

\section{Analysis of Meteorological Drought}

Drought Intensity: The maximum drought intensity SPI2 (June to July) -4.83 in Wilberega in 2004, -2.53 in Hawassa in 2000, -3.61 in Bilate Tena in 2009, -5.55 in Sodo in 1986, -5.85 in Alaba Kulito in 1978, -4.14 in Butajira in 1991, -4.4 in Bilate farm state 2002, -3.95 in Shone in 1981 and -5.08 in Hossana in 1983. From this, we concluded the drought intensity is highest recorded during early Kiremt season in Alaba Kulito early kiremt 
this period important for agricultural production. The maximum drought intensity SPI-3B (February to April) -4.81 in Wilberega in 1981, -6.64 in Awassa in 1984, -5.5 in Bilate Tena in 2008, -6.47 in Sodo in 1986, -6.61 in Alaba Kulito in 1984, -6.39 in Butajira in 2008- 6.31 in Bilate farm state 2002, -6.51 in Shone in 1984 and -5.37 in Hossana in 2008. It can see that for Belg season 1984 and 2008 were severe years, when more than $80 \%$ of the study area was under deficient of rainwater. From this, we concluded that drought intensity is higher than early kiremt in recent years in Belg season, which is important period for short-term agricultural production and land preparation for annual crop production. When Belg season rainfall failed the agricultural product, also decline that means farm depended on rainfall agricultural activity (Figures 3-11).

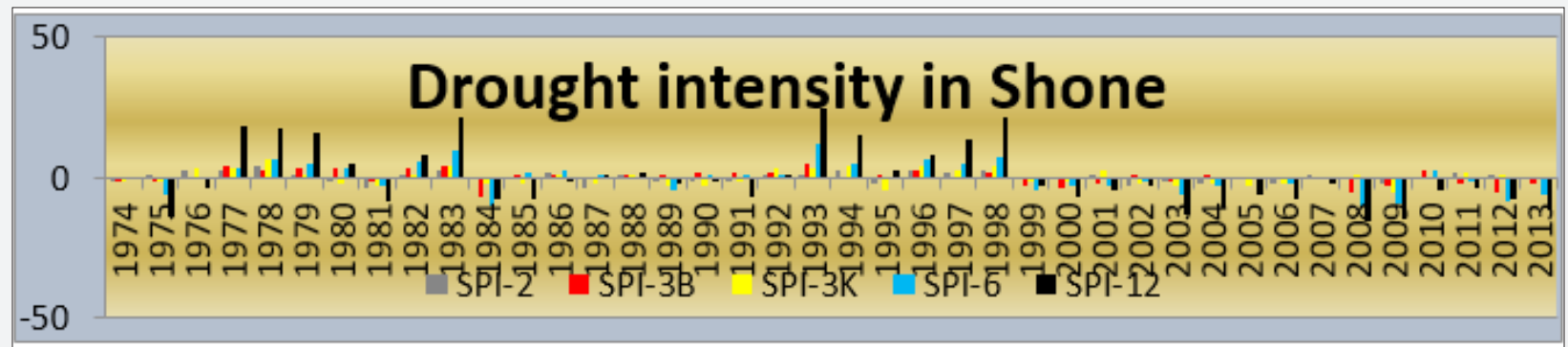

Figure 3: SPI value against time series in Shone.

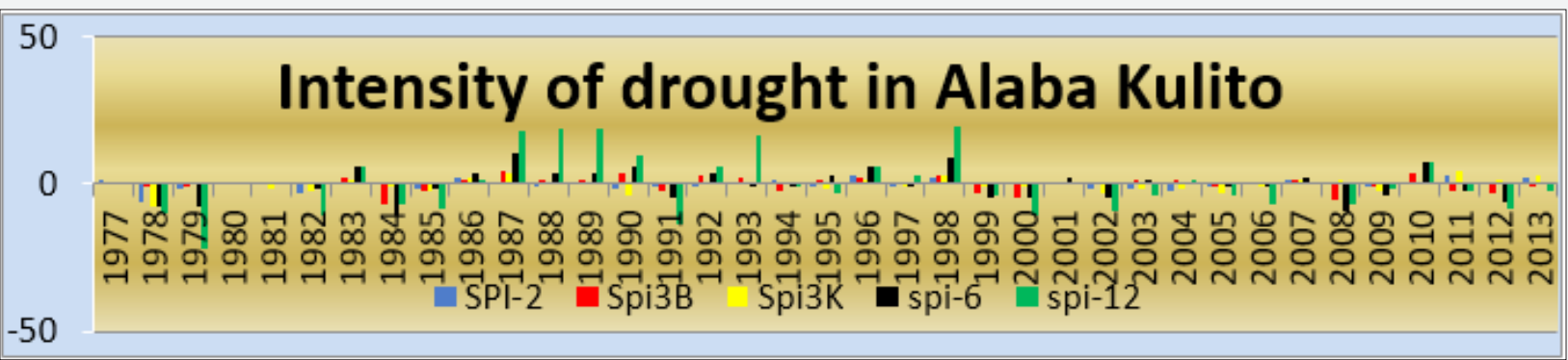

Figure 4: SPI value against time series in Alaba Kulito.

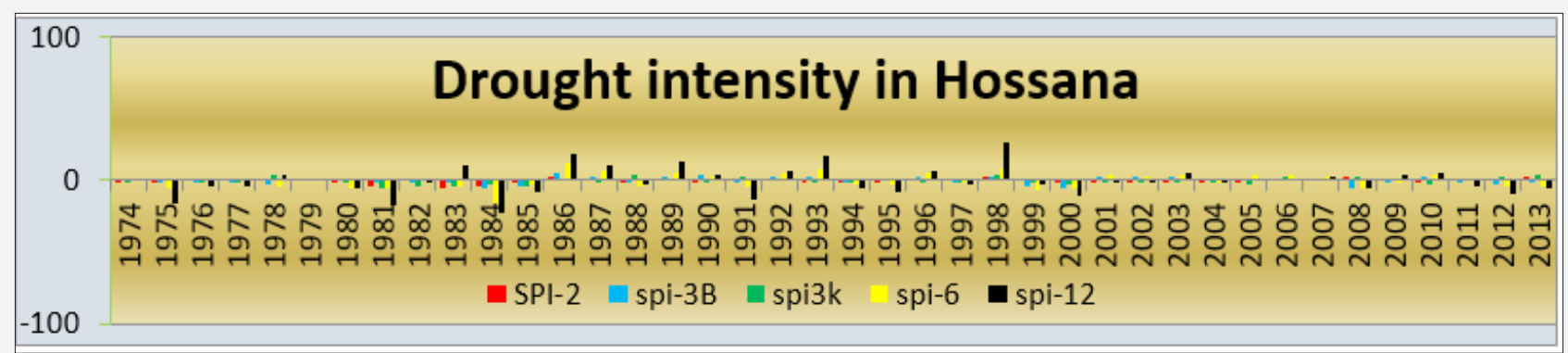

Figure 5: SPI value against time series in Hossana.

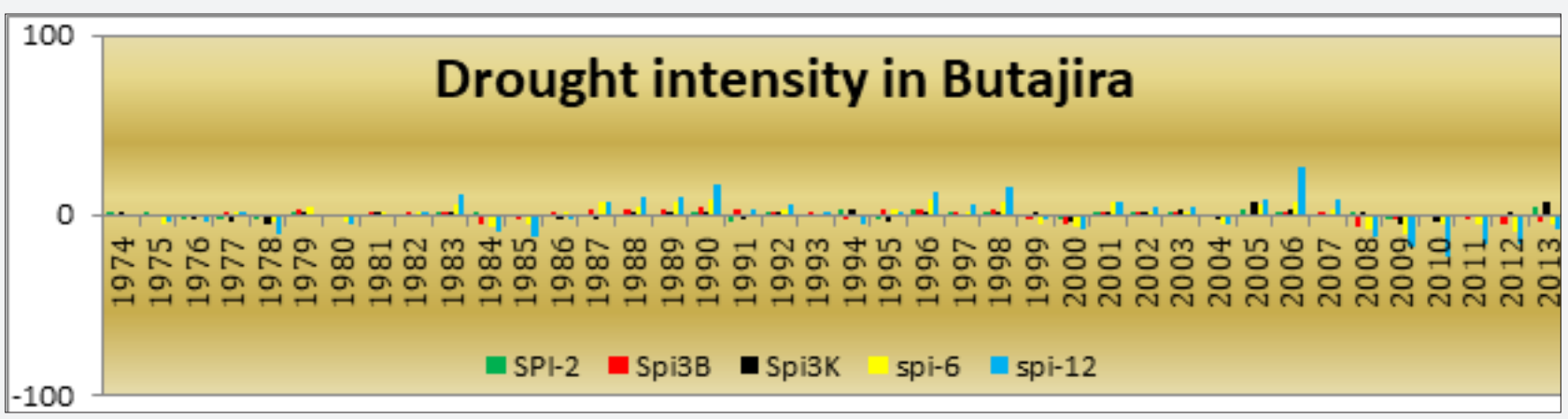

Figure 6: SPI value against time series in Butajira. 


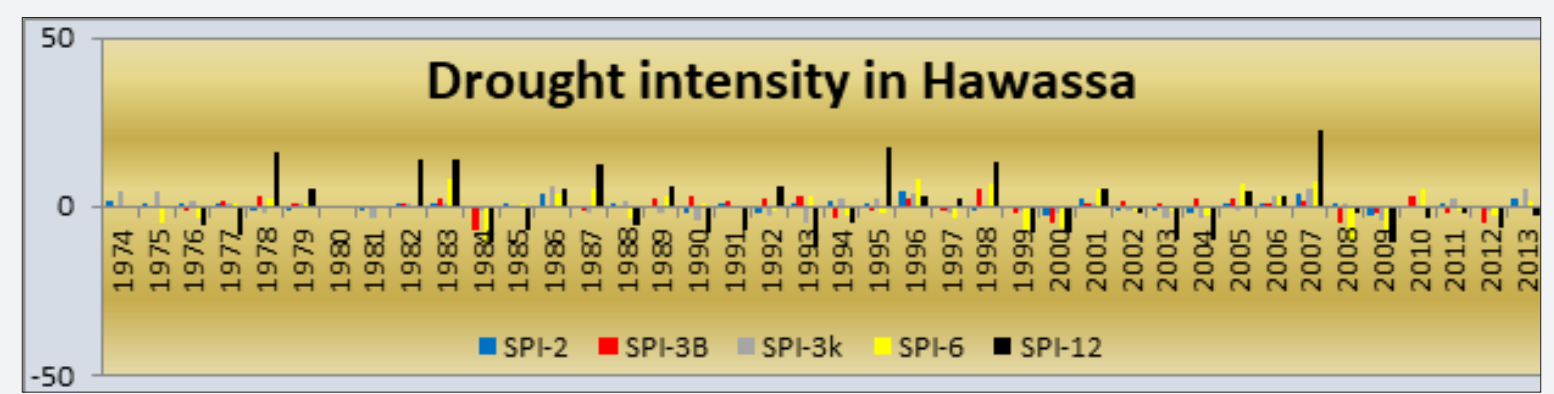

Figure 7: SPI value against time series in Hawassa.

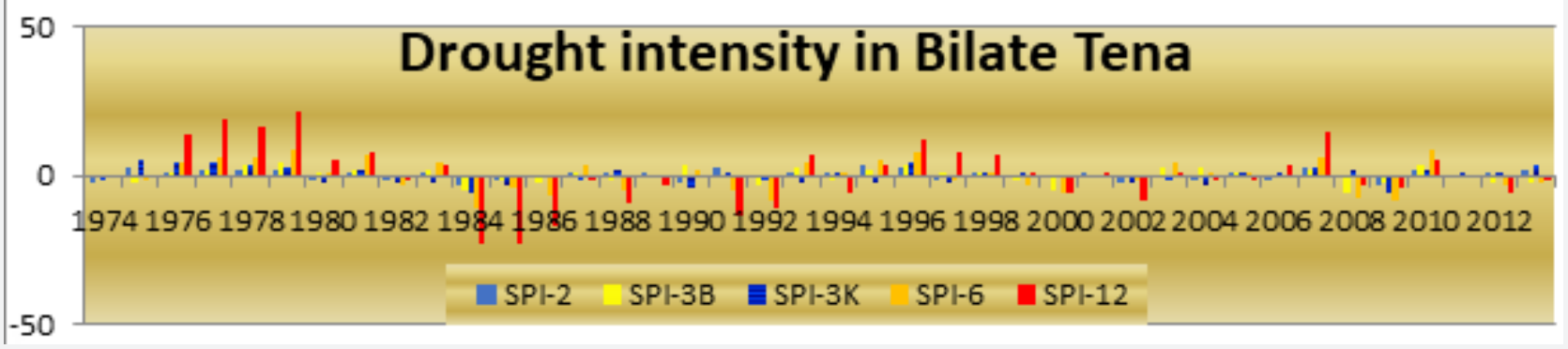

Figure 8: SPI value against time series in Bilate Tena.

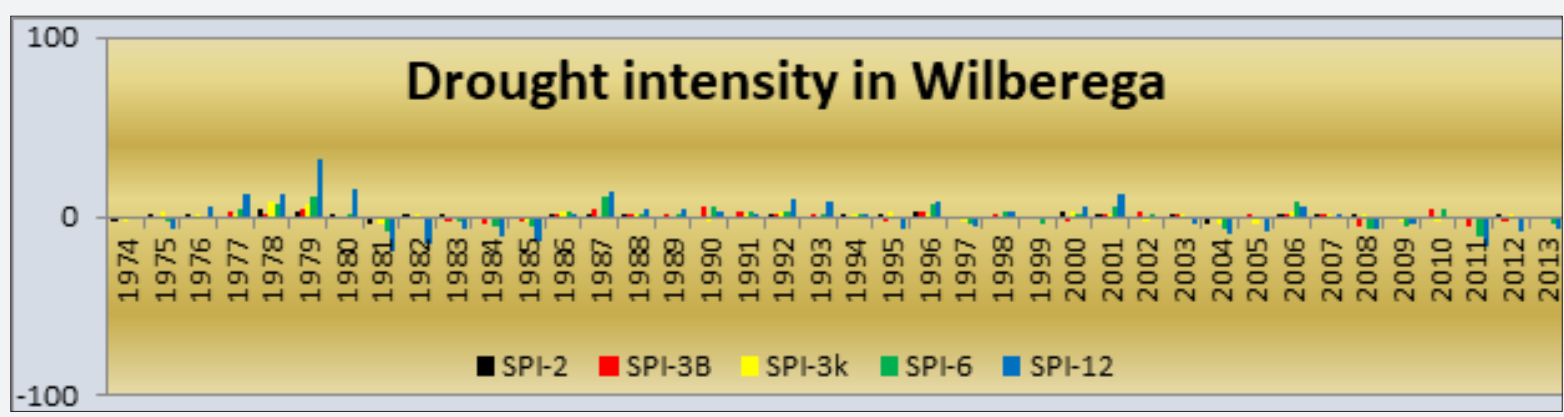

Figure 9: SPI value against time series in Wilbarega.

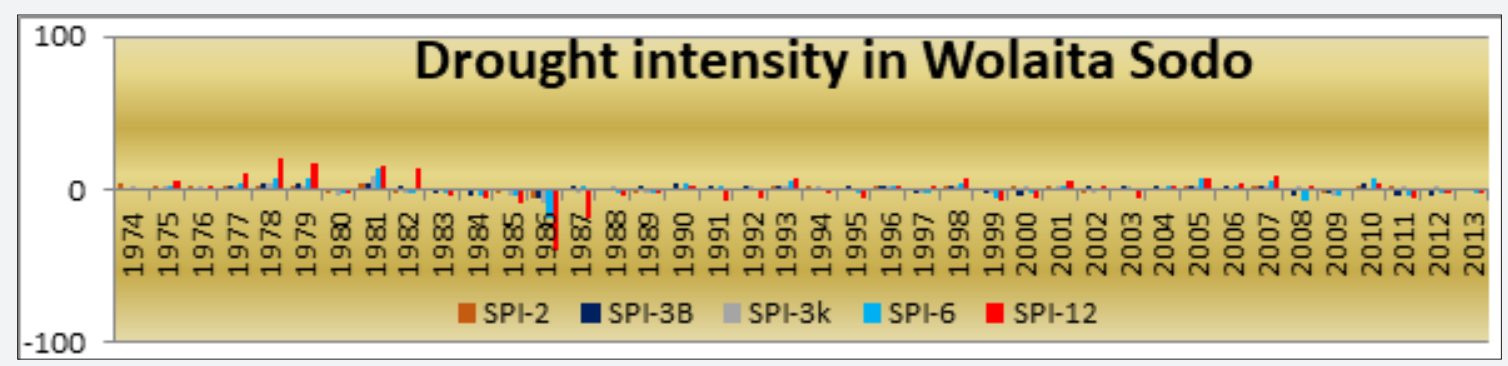

Figure 10: SPI value against time series in Wolaita Sodo.

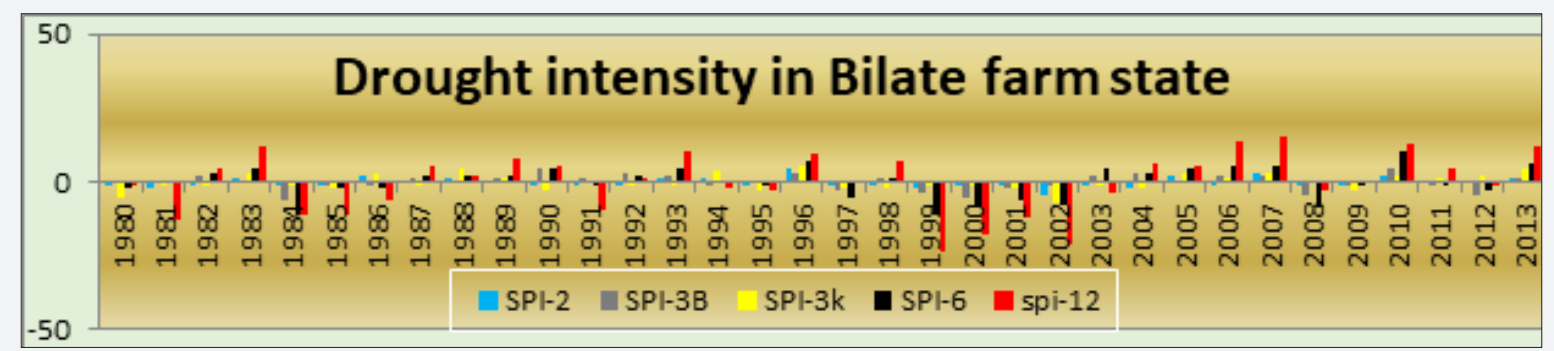

Figure 11: SPI value against time series in Bilate Farm State. 
The maximum drought intensity SPI-3K (July to September) -5.83 in Wilberega in 2009, -4.82 in Hawassa in 1993, -5.82 in Bilate Tena in 2009, -6.65 in Bilate farm state 2002, -9.13 in Sodo in 1986, -7.71 in Alaba Kulito in 1978, -4.66 in Butajira in 2009, -5.4 in Shone in 2009 and -6.04 in Hossana in 1981. From this, we concluded the drought intensity is highest recorded during Kiremt season in Alaba Kulito in 1978, this period important for agricultural production. Based on analysis, Kiremt rainwater showed that the years of low rainwater were 1974, 1978, 1983, 1984, 1987, 1990, 1997, 1999, 2000,2002, 2004, 2008, 2009,2011, 2012 and 2013. The estimated 70\% Kiremt season in 1978, 1984, 1999, 2000 2004, 2009, 2011 and 2012 that extreme drought was affects study area.

The evolution of the SPI for 6-month (SPI-6) rainfall accumulations. The maximum drought intensity SPI-6(March to August) -10.31 in Shone in 1984, -11.44 in Wilberega in 2011, -11.1 in Hawassa in 1984, -11.24 in Bilate Tena in 1984, -11.29 in Bilate farm state in 1999, -19.46 in Sodo in 1986, -10.33 in Alaba Kulito in 1984, -10.28 in Butajira in 2009 and -15.98 in Hossana in 1984. This season is essential seasons for short-term cultivations and annual crop production in study area. As this investigation rainwater was failed in, above-mentioned years due to uncertainty agricultural production were declined. This conclusion is developed because most agricultural activity throughout Ethiopia dependents in rainwater.

Table 6: Drought Severity in Bilate farm
Drought intensity is high in recent years. Drought high intensity starts since 1979 in Alaba kulito, its intensity is -22.89 recorded annual. Next maximum intensity in 1981 happens in Wilbarega. It intensity -18.95 recorded with in period of SPI-12 annual. Third maximum intensity -22.89 recorded in Hossana in 1984 with period of SPI-12. also, in Bilate Tena -22.74 maximum intensity recorded in 1985 annual. Maximum intensity in -23.33 in Bilate farm 1999, and -12.14 Hawassa in 1993. In Shone and Butajira 15.8 and -23.31, recorded annual in 2008 and 2010 respectively. As results of this fact, meteorological droughts were highly taking place in recent decades.

Drought Severity: Severity shows the degree of moisture deficit or surplus. It can be expressed based on SPI value. Severity is single numerical quantities that obtained through cumulative sum of successive negative values. As the results of this fact, severities of drought identified primarily based on SPI values. The highest magnitude of drought severity indicates the highest amount of rainwater deficit during in specified season which shown in table. In general, the result obtained in this study indicates that as the negative value of SPI decreases the severity of the drought increases. From Tables 6-14, Severity of drought was occurred. It possible to concluded that Bilate River Basin were highly deficit in rainwater in the above-mentioned years. Almost all severity happened in recent years.

\begin{tabular}{|c|c|c|c|c|c|c|c|c|c|}
\hline \multicolumn{9}{|c|}{ Drought Severity in Bilate Farm State } \\
\hline SPI-2 & Years & SPI-3B & Years & SPI-3K & Years & SPI-6 & Years & SPI-12 & Years \\
\hline-3.27 & $1980-82$ & -8.31 & $1984-86$ & -7.79 & $1980-82$ & -15.72 & $1984-86$ & -14.64 & $1980-81$ \\
\hline-1.01 & $1984-85$ & -12.69 & $1999-02$ & -2.81 & $1984-85$ & -9.52 & $2008-09$ & -28 & $1984-86$ \\
\hline-1.3 & $1990-92$ & -4.57 & $2008-09$ & -2.51 & $1992-93$ & -4.59 & $2011-12$ & -4.72 & $1994-95$ \\
\hline-11.78 & $1997-04$ & -5.63 & $2011-12$ & -16.93 & $1997-04$ & & & -77.49 & $1999-03$ \\
\hline-2.16 & $2008-09$ & & & & & & & & \\
\hline
\end{tabular}

Table 7: Drought Severity in Hawassa.

\begin{tabular}{|c|c|c|c|c|c|c|c|c|c|}
\hline \multicolumn{10}{|c|}{ Drought Severity in Hawassa } \\
\hline SPI-2 & Years & SPI-3B & Years & SPI-3K & Years & SPI-6 & Years & SPI-12 & Years \\
\hline-2.28 & $1978 / 79$ & -9.09 & $1984 / 88$ & -1.84 & $1984 / 85$ & -8.17 & $1975 / 76$ & -13.59 & $1976 / 77$ \\
\hline-2.54 & $1989 / 90$ & -4.34 & $1994 / 95$ & -14.54 & $1989 / 93$ & -1.23 & $1991 / 92$ & -17.9 & $1984 / 85$ \\
\hline-5.27 & $1997 / 2000$ & -7.15 & $1999 / 2000$ & -9.26 & $2002 / 05$ & -4.66 & $1994 / 95$ & -14.18 & $1990 / 91$ \\
\hline-5 & $2002 / 2004$ & -6.64 & $2008 / 09$ & -3.86 & $2009 / 10$ & -13.24 & $99 / 2000$ & -15.71 & $1999 / 2000$ \\
\hline-2.84 & $2009 / 10$ & -7.75 & $2011 / 13$ & & & -4.54 & $2002 / 4$ & -21.36 & $2002 / 04$ \\
\hline & & & & & & -17.21 & $2009 / 10$ & -26.85 & $2009 / 13$ \\
\hline & & & & & & -3.83 & $2012 / 13$ & & \\
\hline
\end{tabular}


Table 8: Drought Severity in Bilate Tena.

\begin{tabular}{|c|c|c|c|c|c|c|c|c|c|}
\hline \multicolumn{10}{|c|}{ Drought Severity In Bilate Tena } \\
\hline SPI-2 & Years & SPI-3B & Years & SPI-3K & Years & SPI-6 & Years & SPI -12 & Years \\
\hline-5.78 & $1984 / 86$ & -8.79 & $1984 / 86$ & -14.69 & $1982 / 87$ & -22.14 & $1984 / 86$ & -102.59 & $1982-91$ \\
\hline-5.17 & $2002 / 04$ & -2.53 & $1988 / 89$ & -4.61 & $1989 / 90$ & -5.46 & $1988 / 89$ & -3.42 & $2004-05$ \\
\hline-3.67 & $2008 / 9$ & -4.52 & $1991 / 92$ & -4.08 & $1992 / 93$ & -13.41 & $1991 / 92$ & -6.81 & $2008-09$ \\
\hline & & -7.3 & $99 / 2002$ & -7.18 & $2000 / 4$ & -10.65 & $99 / 2002$ & -8.03 & $2010-13$ \\
\hline & & -9.24 & $2008 / 13$ & & & -15.81 & $2008 / 9$ & & \\
\hline & & & & & & -5.74 & $2011 / 13$ & & \\
\hline
\end{tabular}

Table 9: Drought Severity in Wolaita Sodo.

\begin{tabular}{|c|c|c|c|c|c|c|c|c|c|}
\hline \multicolumn{10}{|c|}{ Drought Severity In Sodo } \\
\hline SPI-2 & Years & SPI -3B & Years & SPI -3K & Years & SPI-6 & Years & SPI-12 & Years \\
\hline-16.93 & $1982 / 92$ & -1.91 & $1975 / 76$ & -19.85 & $1982 / 87$ & -31.91 & $82 / 86$ & -83.47 & $83 / 89$ \\
\hline-3.05 & $2002 / 4$ & -13.42 & $1983 / 86$ & -5.19 & $1989 / 91$ & -5.14 & $1988 / 89$ & -12.67 & $1991 / 2$ \\
\hline-2.52 & $2008 / 9$ & -7.62 & $1999 / 2001$ & -4.02 & $2009 / 200$ & -2.58 & $1994 / 95$ & -7.95 & $1994 / 95$ \\
\hline \multirow[t]{4}{*}{-0.78} & $2012 / 13$ & -11.73 & $2008 / 13$ & & & -7.78 & $2009 / 2000$ & -12.46 & $99 / 2000$ \\
\hline & & & & & & -1.66 & $2002 / 3$ & -10.83 & $2011 / 13$ \\
\hline & & & & & & -12.37 & $2008 / 9$ & & \\
\hline & & & & & & -9.45 & $2011 / 13$ & & \\
\hline
\end{tabular}

Table 10: Drought Severity in Wilbarega.

\begin{tabular}{|c|c|c|c|c|c|c|c|c|c|}
\hline \multicolumn{10}{|c|}{ Drought Severity In Wilberega } \\
\hline SPI-2 & Years & SPI-3B & Years & SPI-3K & Years & SPI-6 & Years & SPI-12 & Years \\
\hline-2.05 & $1984 / 855$ & -2.74 & $1974 / 76$ & -4.93 & $1980 / 81$ & -25.11 & $1981-85$ & -65.43 & $1981-85$ \\
\hline-3.45 & $1989 / 91$ & -12.18 & $1980 / 85$ & -3.69 & $1983 / 85$ & -6.99 & $2003-5$ & -24.54 & $2002-5$ \\
\hline-2.14 & $1997 / 99$ & -4.17 & $1994 / 95$ & -3.88 & $1989-90$ & -25.05 & $2007-13$ & -44.85 & $2008-13$ \\
\hline-6.51 & $2004 / 5$ & -3.3 & $1999 / 2000$ & -1.8 & $1997-99$ & & & & \\
\hline-3.72 & $2009 / 11$ & -6.55 & $2008 / 9$ & -8.44 & $2004 / 5$ & & & & \\
\hline & & -9.12 & $2011 / 13$ & -6.42 & $2009 / 11$ & & & & \\
\hline
\end{tabular}

Table 11: Drought Severity in Alaba Kulito.

\begin{tabular}{|c|c|c|c|c|c|c|c|c|c|}
\hline \multicolumn{10}{|c|}{ Drought Severity In Alaba Kulito } \\
\hline SPI-2 & Years & SPI-3B & Years & SPI-3K & Years & SPI-6 & Years & SPI-12 & Years \\
\hline-7.13 & $1978-79$ & -0.98 & $1978-79$ & -3.81 & $1981-82$ & -15.51 & $1978-79$ & -32.21 & $1978 / 79$ \\
\hline-2.74 & $1990-92$ & -8.66 & $1984-85$ & -2.81 & $84-85$ & -12.24 & $1984-85$ & -15.09 & $1984 / 5$ \\
\hline-5.31 & $2002-05$ & -7.78 & $1999-2000$ & -9.29 & $2002-06$ & -2.3 & $1993-94$ & -2.95 & $1994 / 95$ \\
\hline & & -6.3 & $2008-9$ & & & -9.24 & $1999 / 200$ & -14.7 & $1999 / 2000$ \\
\hline & & -6.69 & $2011-13$ & & & -1.36 & $2004 / 5$ & -12.69 & $2002 / 03$ \\
\hline & & & & & & -13.12 & $2008 / 9$ & -14.15 & $2008 / 13$ \\
\hline & & & & & & -8.81 & $2011 / 12$ & & \\
\hline
\end{tabular}

Table 12: Drought Severity in Butajira.

\begin{tabular}{|c|c|c|c|c|c|c|c|c|c|}
\hline \multicolumn{10}{|c|}{ Drought Severity In Butajira } \\
\hline SPI-2 & Years & SPI-3B & Years & SPI-3K & Years & SPI-6 & Years & SPI-12 & Years \\
\hline-6.01 & $76-78$ & -2.12 & $74-75$ & -10.49 & $75-78$ & -5.98 & $75-76$ & -7.44 & $75-76$ \\
\hline-1.11 & $80-82$ & -7.96 & $84-85$ & -6.08 & $84-87$ & -12.5 & $1999-2000$ & -16.93 & $78-81$ \\
\hline
\end{tabular}


International Journal of Environmental Sciences \& Natural Resources

\begin{tabular}{|c|c|c|c|c|c|c|c|c|c|}
\hline-3.19 & $85-89$ & -7.42 & & -8.94 & $2009-11$ & -42.68 & $2008-13$ & -22.53 & $84-86$ \\
\hline-2.54 & & -1.11 & $2004-05$ & & & & & -9.77 & $1999-2000$ \\
\hline-2.54 & & -22.09 & $2008-13$ & & & & & -94.83 & $2008-13$ \\
\hline
\end{tabular}

Table 13: Drought Severity in Hossana.

\begin{tabular}{|c|c|c|c|c|c|c|c|c|c|}
\hline \multicolumn{10}{|c|}{ Drought Severity in Hosanna } \\
\hline SPI-2 & Years & SPI-3B & Years & SPI-3K & years & SPI-6 & years & SPI-12 & years \\
\hline-1.17 & $74-75$ & -6.15 & $75-78$ & -2.5 & $76-77$ & -11.28 & $80-81$ & -23.66 & $75-77$ \\
\hline-4.99 & $1980-81$ & -11.3 & $1982-85$ & -21.59 & $1980-85$ & -23.25 & $1983-85$ & -23.61 & $1980-81$ \\
\hline-11.67 & $1983-85$ & -9.62 & $1999-2000$ & -2.9 & $1993-94$ & -6.88 & $1994-95$ & -30.55 & $1984-85$ \\
\hline-1.72 & $1993-95$ & -7.35 & $2008-9$ & -0.55 & $1996-97$ & -12.05 & $1999-2000$ & -14.11 & $1994-95$ \\
\hline-4.78 & $2000-2006$ & -5.73 & $2011-13$ & -10.63 & $1999-2005$ & -7.63 & $2008-9$ & -15.82 & $1996-97$ \\
\hline & & & & & & -8.71 & $2012-13$ & -20.15 & $1999-03$ \\
\hline
\end{tabular}

Table 14: Drought Severity in Shone.

\begin{tabular}{|c|c|c|c|c|c|c|c|c|c|}
\hline \multicolumn{10}{|c|}{ Drought Severity in Shone } \\
\hline SPI-2 & Years & SPI-3B & Years & SPI-3K & Years & SPI-6 & Years & SPI-12 & Years \\
\hline-5.62 & $1980-81$ & -2.91 & $1974-76$ & -2.58 & $1974-75$ & -6.05 & $1975-76$ & -13.6 & $1975-76$ \\
\hline-3.42 & $1989-91$ & -9.01 & $1999-2001$ & -5.5 & $1980-81$ & -4.55 & $1988-89$ & -16.89 & $1984-87$ \\
\hline-0.42 & $1999-2000$ & -8.77 & $2005-2010$ & -4.86 & $1984-85$ & -43.27 & $1999-2009$ & -10.79 & $1989-91$ \\
\hline-9.11 & $2002-06$ & -9.84 & $2011-13$ & -7.43 & $1989-91$ & -15.51 & $2011-13$ & -114.76 & $1999-2013$ \\
\hline-3.24 & $2008-2010$ & & & -2.53 & $1999-2000$ & & & & \\
\hline & & & & -13.24 & $2002-07$ & & & & \\
\hline & & & & -6.39 & $2009-10$ & & & & \\
\hline
\end{tabular}

\section{Drought Magnitude (Table 15)}

Table 15: Summary for drought duration and magnitude.

\begin{tabular}{|c|c|c|c|c|c|c|c|}
\hline Station & Season & Drought Duration/ Number of Months & \multicolumn{2}{|c|}{ Severity } & \multicolumn{2}{c|}{ Magnitude } \\
\hline & & Maximum & Minimum & Maximum & Minimum & Maximum & Minimum \\
\hline Alaba & SPI-2 & 9 & 2 & -13.41 & -0.09 & -1.49 & -0.045 \\
\hline Kulito & SPI-3B & 15 & 4 & -13.85 & -7.74 & -0.92 & -1.94 \\
\hline & SPI-3K & 13 & 2 & -10.19 & -0.5 & -0.78 & -0.25 \\
\hline & SPI-6 & 20 & 2 & -14.32 & -1.29 & -0.716 & -0.645 \\
\hline & SPI-12 & 20 & 8 & -34.32 & -4.67 & -1.716 & -0.58 \\
\hline Butajira & SPI-2 & 11 & 2 & -8.26 & -0.12 & -0.759 & -0.06 \\
\hline & SPI-3B & 29 & 9 & -29.15 & -9.75 & -1.2 & -1.1 \\
\hline & SPI-3K & 8 & 2 & -4.93 & -0.69 & -0.6 & -0.345 \\
\hline & SPI-6 & 53 & 2 & -66.28 & -0.14 & -1.25 & -0.07 \\
\hline \multirow{2}{*}{ Hossana } & SPI-12 & 70 & 2 & -95.54 & -0.18 & -1.36 & -0.09 \\
\hline & SPI-2 & 10 & 2 & -4.56 & -0.22 & -0.45 & -0.11 \\
\hline & SPI-3B & 8 & 3 & -15.07 & -1.97 & -1.88 & -0.63 \\
\hline & SPI-3K & 8 & 2 & -4.64 & -1.77 & -0.58 & -0.885 \\
\hline & SPI-6 & 18 & 2 & -12.7 & -0.36 & -0.71 & -0.18 \\
\hline & SPI-12 & 32 & 14 & -31.34 & -0.24 & -0.98 & -0.12 \\
\hline
\end{tabular}


International Journal of Environmental Sciences \& Natural Resources

\begin{tabular}{|c|c|c|c|c|c|c|c|}
\hline & SPI-3B & 6 & 2 & -7.22 & -0.75 & -1.21 & -0.375 \\
\hline & SPI-3K & 8 & 9 & -15.07 & -6.45 & -1.88 & -0.72 \\
\hline & SPI-6 & 37 & 2 & -24.09 & -0.28 & -0.65 & -0.14 \\
\hline & SPI-12 & 97 & 2 & -85.8 & & & \\
\hline & -0.59 & $-0 . .88$ & -0.29 & & & & \\
\hline \multirow[t]{5}{*}{ Hawassa } & SPI-2 & 21 & 2 & -4.38 & -0.6 & -0.21 & -0.3 \\
\hline & SPI-3B & 10 & 3 & -4.25 & -2.34 & -0.43 & -0.78 \\
\hline & SPI-3K & 9 & 3 & -12.86 & -2.02 & -1.43 & -0.67 \\
\hline & SPI- 6 & 14 & 2 & -15.99 & -0.71 & -1.14 & -0.355 \\
\hline & SPI-12 & 35 & 2 & -22.43 & -0.08 & -0.641 & -0.04 \\
\hline Bilate & SPI-2 & 15 & 2 & -17.82 & -0.34 & -1.188 & -0.17 \\
\hline \multirow[t]{5}{*}{ Tena } & SPI-3B & 15 & 5 & -20.16 & -3.94 & -1.344 & -0.788 \\
\hline & SPI-3K & 15 & 8 & -20.16 & -8.11 & -1.344 & -1.1 \\
\hline & SPI-6 & 44 & 2 & -49.04 & -0.4 & -1.12 & -0.2 \\
\hline & SPI-12 & 41 & 3 & -66.48 & -0.61 & -1.62 & -0.21 \\
\hline & SPI-2 & 18 & 2 & -36.22 & -0.28 & -2.1 & -0.14 \\
\hline \multirow[t]{4}{*}{ Sodo } & SPI-3B & 19 & 4 & -40.11 & -3.08 & -2.1 & -0.77 \\
\hline & SPI-3K & 19 & 3 & -40.11 & -1.3 & -2.1 & -0.43 \\
\hline & SPI- 6 & 26 & 2 & -52.82 & -0.38 & -2.031 & -0.19 \\
\hline & SPI-12 & 47 & 2 & -72.41 & -0.19 & -1.54 & -0.095 \\
\hline Wilba & SPI-2 & 11 & 2 & -9.29 & -0.1 & -0.84 & -0.05 \\
\hline \multirow[t]{4}{*}{ Rega } & SPI-3B & 16 & 5 & -15.03 & -1.3 & -0.94 & -0.26 \\
\hline & SPI-3K & 8 & 2 & -7.42 & -0.32 & -0.93 & -0.16 \\
\hline & SPI- 6 & 22 & 2 & -27.11 & -0.29 & -1.23 & -0.145 \\
\hline & SPI-12 & 70 & 2 & -68.37 & -0.27 & -0.97 & -0.135 \\
\hline Bilate & SPI-2 & 16 & 2 & -15.97 & -0.25 & -0.99 & -0.13 \\
\hline \multirow[t]{4}{*}{ Farm } & SPI-3B & 30 & 8 & -28.91 & -4.44 & -0.96 & -0.55 \\
\hline & SPI-3K & 30 & 2 & -28.91 & -0.7 & -0.96 & -0.35 \\
\hline & SPI-6 & 29 & 2 & -24.76 & -2.05 & -0.85 & -1.1 \\
\hline & SPI-12 & 56 & 2 & -81.97 & -0.27 & -1.45 & -0.14 \\
\hline
\end{tabular}

Drought Frequency: Drought frequency is the ratio between the number of events of certain intensity, and the total duration of time series. The probability of occurrence of drought is different by its intensities (Mild ( 0 to -0.9 ), moderates $(-0.9$ to -1.49$)$, severe $(-1.49$ to -1.9$)$ and extreme (<-2)). This intensity of drought categorized based on SPI value. The frequencies of different type of drought intensity namely mild, moderates, severe and extreme drought were uneven distribution in the study area. In general, the extreme drought is more frequent than mild, moderate and severe drought. From this, we concluded all droughts occur in certain degree, but extreme droughts were the most common types of droughts in Bilate River Basin.

Spatial Extent of Meteorological Drought (Figure 12) 


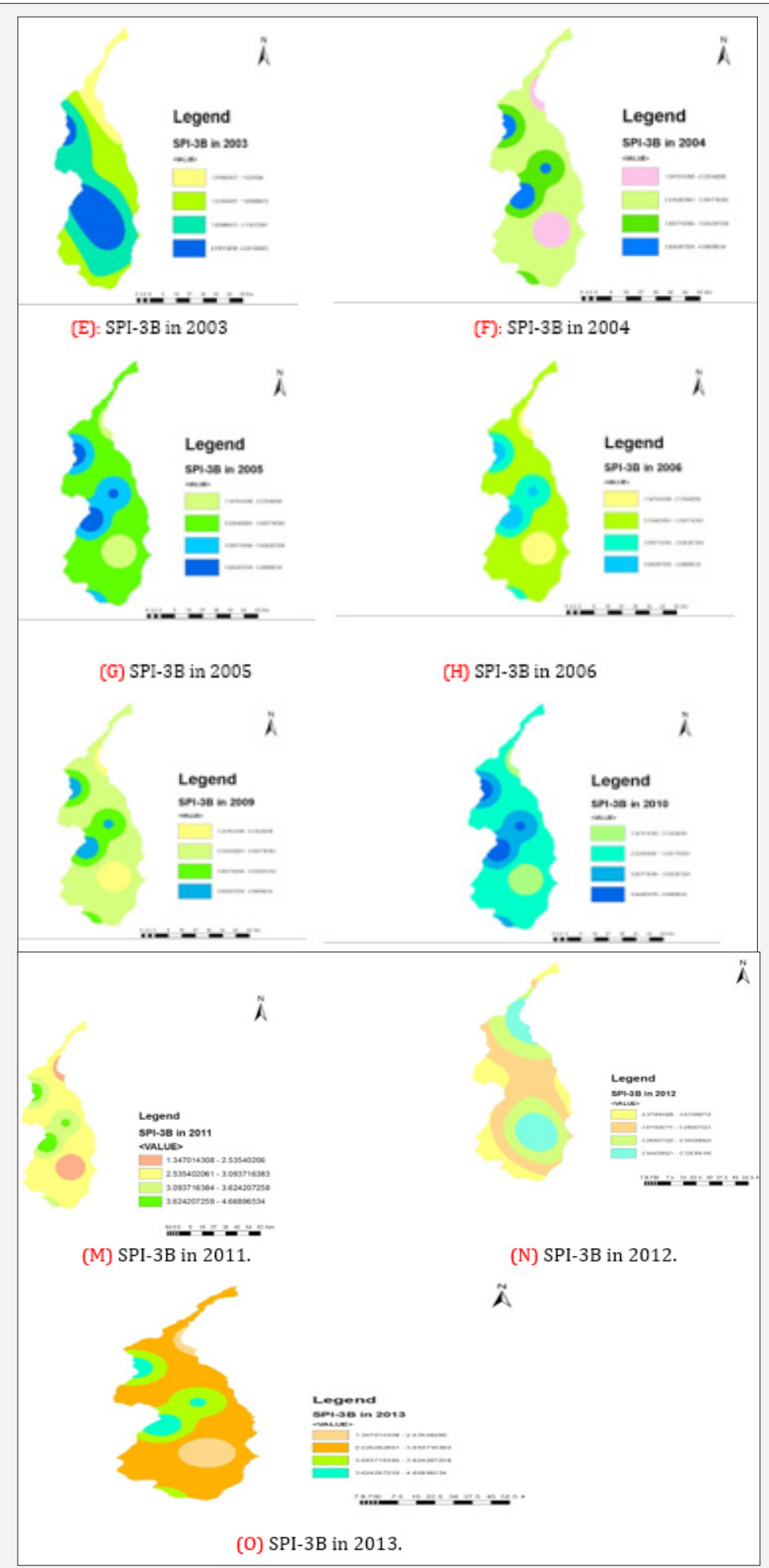

Figure 12: Spatial extents of SPI-3B from 2003-2013.

\section{Conclusion}

This study has presented analysis of the spatial and temporal variability of rainfall and meteorological drought using rainfall data obtained from fourteen meteorological stations of around Bilate River Basin from the year 1974 to 2013. The result showed that there was considerable spatial variation of rainfall in Bilate
River Basin which analyzes based on coefficients of variations. During Belg season highly variability was predominated than Kiremt season. Annual coefficients variation was not greater than 30. Maximum CV were 41\%, 37\%, and 29\% in Belg (Alaba Kulito), Kiremt (Sodo) and Annual (Sodo) respectively. Trend analysis on annual and seasonal rainfall amounts trend test results show that there is no more significant trend in the annual and seasonal 
rainfall almost in all Bilate River Basin station due to large interannual fluctuations. For this reason, the trend evaluation indicates there is unstable trend almost in all station. In Butajira and Shone the trend statistically significant. This means there is strictly decreasing trends in shone both annual and Belg seasons where as in Butajira increasing trends Kiremt and decreasing Belg seasons at $\alpha=.1, \alpha=.05, \alpha=.01$ level with critical statistic table value 1.645, 1.96 , and 2.576 respectively. Annual rainfall is increasing trend at Angacha, Bedessa Bilata fram, Humbo Tebele, Hossana and Bilate Tena, whereas decreasing trend at Fonko, Hawassa, Butajira, Boditi, sodo, Shone, Wilbarega and Alaba Kulito.

Rainfall is highly correlated with ENSO in around Bilate River Basin. El Niño enhances rainfall activities and La Niña periods lowering rainfall. La Nina episode decrease the amount of rainfall in Belg season and increase the amount of rainfall in Kiremt, while El Nino increase the amount of rainfall in Belg and decrease the amount of rainfall in Kiremt season of the regime. The duration of drought is the number of successive months in which the SPI value is in mild, moderate, severe or extreme conditions. The results showed that the 10 months minimum and 21 months maximum drought duration of SPI-2 were recorded in Hawassa and Hossana respectively. The six minimum and thirty maximum month's drought duration of SPI-3B were recorded in Shone and Bilate farm state respectively. SPI-3K season drought duration recorded eight minimum and thirty maximum months drought duration in Shone and Bilate farm respectively. The maximum drought duration recorded 97 months in Shone during SPI-12 and 53 months in Butajira during SPI-6 seasons respectively.

Drought magnitude is one of basic drought parameter calculated by the ratio of severity to duration. The severity per duration creates an impact of certain drought magnitude. The highest drought magnitude observed in Sodo when comparing with all seasons which magnitude is -2.1 in SPI-3B and SPI-3K seasons. Next to Sodo is Shone and Hossana its magnitude is -1.88 in SPI -3B seasons. Consecutive SPI-3K (Kiremt) and SPI-3B (Belg) drought map of recent years (2003-2013) was interpolated through ordinary Kriging method.

\section{References}

1. Abdissa Mohammed (2006) Drought analysis of east Orom, harar and Dire Dawa, Msc thesis in Arba Minch University, Ethiopia.

2. Gibbs WJ, Maher JV (1967) Rainfall deciles as drought indicators Bureau of Meteorology Bulletin no. 48. Commonwealth of Australia, Melbourne, UK.

3. Keyantash J, Dracup JA (2002) The quantification of drought: An evaluation of drought indices. Bull Amer Meteor Soc 83: 1167.

4. McKee (1993) The Relationship of drought Frequencyand Duration to time scales, Eighth Conference on Applied Climatology. Department of Atmospheric Science, Anaheim, California, USA.

5. NMSA (1996) Assessment of drought in Ethiopia. Meteorological research report series, National Meteorological Services Agency of Ethiopia, Addis Ababa, Ethiopia.

6. NMSA (1998) Annual Climate Bulletin. Addis Ababa, Ethiopia.

7. NOAA (2014) Cold and warm episodes by season, Climate Prediction Center.

8. Palmer W (1965) Meteorological drought. Technical report, US Weather Bureau Research Paper 45, USA.

9. Seleshi Y, Zanke U (2004) Recent changes in rainfall and rainy days in Ethiopia. Int J Climatol 24: 973-983.

10. Yenigun K, Gumus V, Bulut H (2008) Trends in stream flow of the Euphrates basin, Turkey. Proc Inst Civil Eng Water Manage.

11. Yitea Seneshaw (2012) Spatial Temporal analyses of climate elements, vegetation characteristics and sea surface temperature anomaly. A case study in Gojam, Ethiopia.

This work is licensed under Creative

Commons Attribution 4.0 License

DOI: 10.19080/IJESNR.2018.14.555891
Your next submission with Juniper Publishers will reach you the below assets

- Quality Editorial service

- Swift Peer Review

- Reprints availability

- E-prints Service

- Manuscript Podcast for convenient understanding

- Global attainment for your research

- Manuscript accessibility in different formats

(Pdf, E-pub, Full Text, Audio)

- Unceasing customer service

Track the below URL for one-step submission https://juniperpublishers.com/online-submission.php 